\title{
Letter to the editor: Rabid puppy-dog imported into the Netherlands from Morocco via Spain, February 2012
}

P Santa-Olalla Peralta (psantaolalla@msssi.es) ${ }^{1}$, J M Mayoral Cortés ${ }^{2}$, M J Sierra-Moros ${ }^{1}$

1. Centro de Coordinación de Alertas y Emergencias Sanitarias (Coordinating Centre for Health Alerts and Emergencies), Ministerio de Sanidad, Servicios Sociales e Igualdad (Ministry of Health, Social Services and Equity), Madrid, Spain

2. S.G. Salud Pública y Participación, Consejería de Salud, Junta de Andalucía (Regional Ministry of Health, Andalusian Regional Government), Spain

Citation style for this article:

Santa-Olalla Peralta P, Mayoral Cortés JM, Sierra-Moros MJ. Letter to the editor: Rabid puppy-dog imported into the Netherlands from Morocco via Spain, February 2012.

Euro Surveill. 2012;17(12):pii=20123. Available online: http://www.eurosurveillance.org/ViewArticle.aspx?Articleld=20123

Article published on 22 March 2012

To the editor: We read with interest the article by van Rijckevorsel et al. on a rabid puppy-dog imported into the Netherlands from Morocco via Spain, recently published in Eurosurveillance [1]. We would like to complete the information on this event with actions taken by the Spanish health authorities and lessons learnt.

On 16 February 2012, Thursday afternoon, the Coordinating Centre for Health Alerts and Emergencies at the Ministry of Health in Spain received a selective message via the Early Warning and Response System (EWRS) from the Dutch health authorities, communicating the laboratory confirmation of rabies in a puppydog from Morocco that had been imported into the Netherlands via Spain. The dog was transported by car from Morocco to Spain by a Dutch couple who stayed in Spain for a week before departure by plane to the Netherlands. Dutch authorities informed that a risk exposure had been identified in at least three persons living in Spain (Contacts 1, 2 and 3). These persons had already been informed by the Public Health Service Amsterdam with the advice to seek medical care for post-exposure prophylaxis.

Upon reception of this message, immediate public health action was initiated in Spain:

A request for more information such as the name of the hotels where the couple had stayed in Spain, dates, itinerary and contact details of the contacts living in Spain was made in order to complete contact tracing and start prophylaxis. Information on the couple's itinerary, hotels and restaurants visited, and on human and animal contacts of the dog was obtained from different sources the following day, after active request from the Spanish authorities.

Information available at that time was sent to the Spanish Alerts' Network (consisting of public health professionals at national and regional level and other sectors involved in detection and response) and an alert concerning this event was issued to the regional public health authorities who alerted their regional health services and started an active search for possible contacts at risk in hotels and places visited by the Dutch couple, once this information was available on the evening of 17 February. Health centres and veterinary services serving the area concerned were also contacted to make sure that no people seeking medical attention for dog bites or any incident with a dog had been reported. As a result of these actions, no further human or animal contacts were identified in addition to the first three human contacts identified by Dutch authorities.

Contact details of contacts living in Spain were at no time accessible for the Spanish authorities because of Dutch national laws which do not allow the disclosure of personal data. This delayed public health action in Spain and caused unnecessary difficulties. For instance, as instructed by phone by the Dutch authorities, Contacts 1 and 2 sought medical care on 16 February, before the Spanish authorities were informed of this event. This caused confusion in the healthcare centre as in mainland and insular Spain there has not been any rabies in terrestrial animals since 1975 . Following current protocols, Contacts 1 and 2 were asked to provide a written proof of their exposure history, while adequate healthcare and follow-up were organised the same day. Post-exposure prophylaxis (first dose of vaccine) was given after they presented email documentation from the Dutch National Institute for Public Health and the Environment mentioning the laboratory confirmation of rabies in the puppy. Human rabies immunoglobulin was available on the morning of 17 February but both contacts failed to show and left the country that evening without informing Spanish health authorities.

Contact 3 could not be followed until they contacted Spanish health authorities several days later. Despite being informed of the exposure risk and offered 
prophylaxis following current protocols, this contact refused to take it.

A summary of the control measures taken in Spain was posted on the EWRS site on 23 February 2012.

An internal evaluation of this event has shown the need to reinforce the appropriate control at customs and following of European Union (EU) legislation on non-commercial movement of pet animals [2]. We also think that the public should be made aware through travel advice of the risks and their responsibility when bringing back animals from abroad [1].

Lessons learnt also include difficulties in accessing personal information within the EU despite efforts made by the European commission and the EU Member States, as well as the need to respect official channels for communication with contacts living in another Member State. Public health activities to be carried out in a given country should be managed by the health authorities of that country who are responsible for risk management in their territory and know the current protocols and response mechanisms in place. The use of channels other that those established in each country can create dysfunction for all actors involved in the response, including a deficient attention to the exposed or affected population.

\section{References}

1. van Rijckevorsel GG, Swaan CM, van den Bergh JP, Goorhuis A, Baayen D, Isken L, et al. Rabid puppy-dog imported into the Netherlands from Morocco via Spain, February 2012. Euro Surveill. 2012;17(10): $\mathrm{pii}=20112$. Available from: http://www. eurosurveillance.org/ViewArticle.aspx?Articleld=20112

2. European Commission. Regulation (EC) No $998 / 2003$ of the European Parliament and of the Council of 26 May 2003 on the animal health requirements applicable to the noncommercial movement of pet animals and amending Counci Directive 92/65/EEC. Official Journal of the European Union. Luxembourg: Publications Office of the European Union. 13 Jun 2005:L 146. Available from: http://ec.europa.eu/food/animal/ liveanimals/pets/reg_998_2003_en.pdf 